\title{
Concepções e atuação profissional diante das queixas escolares: os psicólogos nos serviços públicos de saúde
}

\author{
Estela Cabral \\ Sandra Maria Sawaya \\ Universidade de São Paulo
}

\begin{abstract}
Resumo
Este trabalho tem o objetivo de conhecer a atuação dos psicólogos diante das queixas escolares de crianças encaminhadas aos serviços públicos de saúde do município de Ribeirão Preto, Estado de São Paulo, uma vez que ela pode fornecer dados importantes para a análise da formação profissional do psicólogo. Foram realizadas entrevistas individuais, semi-estruturadas a partir de um roteiro, sendo estas gravadas e transcritas, o que permitiu uma análise quantitativa e qualitativa das respostas de 19 psicólogos que participaram do presente estudo. Os resultados mostraram que esses profissionais ainda compreendem a queixa escolar como um problema da criança pobre e de sua família, passível de ser analisado e tratado fora do contexto da instituição escolar, na qual o fracasso escolar é produzido. Embora os profissionais apontem a participação da escola na produção das dificuldades escolares das crianças, o foco de intervenção dos problemas apresentados ainda é o atendimento individualizado das crianças e dos seus familiares. Apesar dos avanços teórico-metodológicos presentes nas novas compreensões das queixas escolares, eles ainda não se fazem suficientemente presentes na atuação desses profissionais.
\end{abstract}

Palavras-chave: Formação profissional e Psicologia, Problemas de aprendizagem, Atuação do psicólogo.

\begin{abstract}
Conceptions and professional performance in face of the needs of children with school problems: Psychologists in the public health services This work aims at characterizing the performance of psychologists in the public health services in the City of Ribeirão Preto, São Paulo State, in face of the needs of children presenting school problems, since they can be an important source of information for the education of such professionals. Individual semi-structured interviews were recorded and transcribed, allowing quantitative and qualitative analyses of data from 19 psychologists who participated in this study. The results showed that psychologists still regard school problems as inherent to poor children and their families and that they can be treated out of the contexts in which they were produced - the school institution where the complaint has originated. Although professionals point out the participation of the school in the production of children's difficulties, the focus of intervention in problems presented is still the individualized assistance to children and their families. In spite of the theoretical and methodological improvements found in the new understanding of school problems, they are still not present in the performance of these professionals.
\end{abstract}

Key-words: Professional education and psychology, Learning problems, Psychologist's performance.

É conhecida a enorme quantidade de crianças com queixas escolares encaminhada pelas escolas aos psicólogos nos Centros de Saúde. Estudos revelam que 50 a $70 \%$ das crianças e adolescentes encaminhados aos serviços públicos de saúde têm como queixa dificuldades de aprendizagem ou problemas de comportamento na sala de aula ou fora dela (Machado, 1991; Souza, 1993). Nesta úl- tima década, várias pesquisas (Boarini, Guimarães \& Luzia, 1990; Mello, 1997; Patto, 1990; Santos, 1990; Silva, 1994) têm analisado criticamente as concepções e o direcionamento que a Psicologia tem dado ao atendimento das queixas escolares, no momento em que os psicólogos deixaram de exercer atividades nas escolas e centralizaram sua atuação nos Centros de Saúde. Além disso, essas pes- 
quisas vêm propondo aos psicólogos que atendem crianças e adolescentes com queixas escolares novas perspectivas de atuação profissional (Machado \& Souza, 1997).

O presente estudo tem por objetivo analisar se as contribuições destas pesquisas críticas vêm sendo incorporadas pelos psicólogos em sua atuação nos serviços públicos de saúde do município de Ribeirão Preto-SP e também discutir questões que envolvem a formação profissional do psicólogo, tendo em vista que as novas políticas educacionais têm tornado urgente essa discussão.

Já na década de 80, Patto (1987), com o objetivo de conhecer a maneira como os psicólogos representavam a realidade social e escolar e o desempenho desses profissionais nas escolas no município de São Paulo, chamava a atenção para os equívocos e incompreensões presentes na formação do psicólogo em relação ao atendimento dos problemas escolares das crianças provenientes das camadas populares. Convictos de que os alunos eram deficientes e/ou diferentes e que os professores não os compreendiam em suas deficiências (p. 173), a atuação dos psicólogos focalizava dois aspectos: os alunos e os professores. Com o intuito de desenvolver nos alunos atitudese comportamentos esperados pela escola, realizavam treino de agilidade motora, trabalhavam com a disciplina e obediência às regras escolares, isto é, buscavam a integração da criança desajustada aos padrões de comportamento desejados e a eliminação dos comportamentos inadequados (p. 185). Com os professores, o trabalho voltava-se à sensibilização deles para os aspectos educacionais tais como a discussão do processo de aprendizagem e suas dificuldades, buscando auxiliá-los no desempenho mais eficiente da sua tarefa, embora não discutissem as posturas autoritárias que poderiam estar influenciando os comportamentos indesejados dos alunos. Todavia, quando os psicólogos eram questionados sobre a eficácia de sua proposta de atuação, mostravam-se muito insatisfeitos com esta forma de trabalho com os alunos e os professores, sentindo-se angustiados e impotentes diante do fraco resultado que obtinham (p. 186).

Nessa mesma direção, Almeida (1992), com o objetivo de investigar e compreender as concepções que os psicólogos escolares tinham das dificuldades de aprendizagem, verificou que eles acreditavam que tais dificuldades advinham de deficiências dos alunos, de atraso cognitivo ou de problemas emocionais, relacionados à desestruturação familiar, isentando a escola, os fatores psicopegagógicos e o processo ensino-aprendizagem da responsabilidade pelos problemas escolares (p. 265). Tal postura levava os psicólogos a direcionarem a sua atuação apenas para os aspectos individuais do aluno.

Da mesma forma, Yamamoto et al. (1990), mostrando a situação da Psicologia Escolar em Natal (RN) e caracterizando o trabalho desenvolvido pelos psicólogos nesta cidade, observou que a maior atenção centrava-se no aluno, fi- cando em segundo plano a atuação junto à escola, aos professores e aos pais.

Em uma outra direção de estudos, Silva (1994), fazendo um levantamento da demanda infantil por atendimento psicológico em um Centro de Saúde-Escola da Faculdade de Medicina de Ribeirão Preto (SP), verificou que era grande a quantidade de crianças encaminhadas com queixa escolar e, assim, mostrou que o sistema educacional fundamental tinha a tendência a atribuir as dificuldades escolares dos alunos a problemas intrapsíquicos e/ou orgânicos. Em outras palavras, as causas das dificuldades de aprendizagem, antes atribuídas às condições adversas de saúde (como a desnutrição e verminoses) das classes menos favorecidas da sociedade, passaram a ser atribuídas também aos problemas psicológicos (p. 39), o que levou ao aumento da procura por serviço de psicologia infantil nos centros de saúde.

Fazendo uma análise das estratégias de atuação do psicólogo nestas queixas, Souza (1993) revela que muitas vezes este profissional de saúde não consegue compreender claramente o motivo pelo qual a criança foi encaminhada para o serviço de psicologia. Tampouco a família ou a criança sabem explicar os motivos do encaminhamento. E, em algumas ocasiões, "durante o processo de psicodiagnóstico, as mães trazem informações da escola dizendo que seu filho havia deslanchado no aprendizado, sem que se tivesse ainda por parte do psicólogo qualquer dado mais concreto a respeito das causas da problemática dessas crianças, apontadas pela escola" (p. 270). Tais fatos, somados a vários outros, como a atribuição, pelos psicólogos, de possíveis causas emocionais aos problemas escolares, têm revelado o seu desconhecimento a respeito da escola de onde vêm essas crianças e o que se passa em seu interior.

Oliveira e Bruns (1992), com o objetivo de caracterizar a atuação dos psicólogos que trabalham nas redes de ensino na cidade de Ribeirão Preto - SP e região, apontou o quanto a legislação favorece o trabalho de diagnóstico do psicólogo nas escolas. A lei, ao exigir avaliação psicológica no encaminhamento de crianças para classes especiais, fortalece a atuação do psicólogo como avaliador do desempenho da criança, de forma que o sistema ajuda a acentuar uma imagem reducionista do aluno, valorizando a avaliação psicométrica (p. 49). Concluem ainda que, apesar de as escolas reconhecerem a importância do serviço de psicologia, há necessidade de uma revisão crítica da identidade do psicólogo escolar e da especificação de seu papel profissional (p. 50) para que, de fato, ele possa auxiliar as escolas no equacionamento das dificuldades escolares.

Na mesma direção, partindo de considerações históricas para mostrar a contribuição da Psicologia à Educação, Del Prette (1993) aponta que a atuação do psicólogo tem sido fortemente influenciada por um referencial teórico-metodológico advindo da Psicologia Clínica, o qual limita sua 
atuação profissional na instituição escolar, por focalizar os aspectos individuais do aluno. Assim, mostra necessidade de reconstruir a identidade do psicólogo no contexto educacional, revendo as concepções e práticas profissionais de modo a que elas possam dar conta da complexidade dessa realidade. Propõe, ainda, uma ampliação da concepção da queixa escolar que focalize não só a criança mas também a identificação de fatores intra-escolares associados a estas queixas, de modo a tornar possível uma intervenção mais adequada sobre as reais necessidades da escola e dos alunos.

Nos últimos 20 anos, alguns estudos em Educação e em Psicologia (Andaló, 1993; Del Prette, 1993; Gatti, Patto, Costa, Copit \& Almeida, 1981) realizaram uma análise crítica das práticas pedagógicas, da relação professor-aluno, da estrutura e funcionamento da escola pública oferecida às crianças e adolescentes de camadas populares, revendo ainda as concepções que a escola tem do aluno e de sua família e o seu modo de atuação junto a eles. Estes estudos vêm apontando causas intra-escolares para os altos índices de fracasso escolar e, como mostrou Ribeiro (1991) em 1982, estudos registravam $52 \%$ de reprovação da primeira para a segunda série do primeiro grau. Tais estudos permitiram uma ampliação do entendimento dos problemas escolares desta clientela, abrindo novas perspectivas de investigação e atuação do psicólogo na escola.

A partir de um referencial teórico-metodológico que permitiu uma análise do cotidiano escolar, alguns estudos (Collares \& Moyses, 1996; Patto, 1990) vieram revelar que o fracasso escolar das crianças da camadas populares é produzido por diversas práticas que se estabelecem na relação da escola com a sociedade e com sua clientela, tais como a elaboração de materiais didáticos distantes da realidade das crianças, por crenças de que esta população não aprende porque é portadora de deficiências decorrentes de suas condições de vida ou pelas dificuldades econômicas que não lhe permitem se alimentar direito, ou pela falta de interesse dos pais por questões escolares, ou pela desestruturação familiar, crenças que acabam interferindo no relacionamento com os alunos, pois desacreditando neles, os professores acabam por não lhes ensinar, rotulando-os como deficientes. A partir de tal análise, abriram-se novas perspectivas de atuação do psicólogo nas queixas escolares.

Nessa mesma linha de pesquisa, Andaló (1993) veio revelar que os modos de atuação do psicólogo também têm contribuído para o não entendimento da multiplicidade de fatores intra-escolares na produção das dificuldades das crianças de camadas populares. Permeada por concepções e representações muitas vezes baseadas em preconceitos sociais em relação às crianças pobres e suas famílias, as práticas dos psicólogos acabam por reforçar os "mecanismos ideológicos" (a avaliação negativa do professor sobre as capacidades de aprendizagem das crianças e suas repercus- sões sobre a família, entre outros), "que naturalizados através de um processo de interiorização que faz com que passem a fazer parte da subjetividade", traduzem-se em formas de relacionamento que produzem dificuldade de aprendizagem do aluno (p. 5).

Complementando esta idéia, Balbino (1990) aponta também a desarticulação entre teoria e prática que caracteriza a formação do psicólogo, bem como a falta de um enfoque sócio-político que permita, inclusive, aos psicólogos terem um conhecimento dos dados e informações sobre a situação da educação brasileira (p. 55).

É no contexto dessas discussões que o presente estudo se insere e visa caracterizar a atuação de psicólogos que atendem crianças encaminhadas com queixas escolares aos serviços públicos da cidade de Ribeirão Preto (SP), sejam eles municipais, estaduais ou ligados a entidades não-governamentais.

Buscando conhecer como os psicólogos compreendem o seu trabalho e desempenham profissionalmente, este artigo pode contribuir para o entendimento dos problemas por eles enfrentados, ajudando-os a reconhecer, a partir de uma análise das concepções que permeiam sua atuação profissional, quais as questões que precisam ser enfrentadas na superação desses problemas.

\section{Método}

\section{Amostra}

Participaram do presente estudo dezenove psicólogas que atuam na cidade de Ribeirão Preto (SP) em serviços públicos - Unidades Básicas de Saúde, Clínicas Escolas e Centros Especializados - que atendem crianças encaminhadas com queixas escolares.

As psicólogas entrevistadas constituem uma representativa amostra de $60 \%$ do total de 32 profissionais que atuam nos diferentes tipos de serviços públicos prestados ao município, o que permite uma caracterização de suas atuações profissionais junto às crianças com queixas escolares encaminhadas pelas escolas estaduais e municipais deRibeirão Preto aos serviços públicos dePsicologia.

As profissionais têm grande experiência profissional e alto nível de qualificação, 58\% delas têm mais de 10 anos de formados e $10 \%$ mais de 3 anos de formados e $53 \%$ delas estão há pelo menos 5 anos neste emprego. Formadas em sua grande maioria em universidades públicas, $64 \%$ delas cursaram a Faculdade de Filosofia, Ciências e Letras de Ribeirão Preto da USP, sendo que 63\% têm especialização pela Faculdade de Medicina de Ribeirão Preto da USP, na área de atendimento de saúde (Psicopedagogia, Psicologia cCínica com especialização no atendimento a crianças e adolescentes). Dessas profissionais, $26 \%$ possuem mestrado e $5 \%$ doutorado na área de educação. 
Em sua maioria (73,6\%), as psicólogas acumulam outras atividades profissionais: consultório particular, atividades em centros de educação especial, supervisão de outros profissionais, trabalho em prefeitura e docência universitária. Mais da metade delas (63\%) já atuaramem instituições de ensino, seja como "psicólogas clínicas" (37\%), seja como "psicólogas em centros de educação especial" (10,5\%) ou ainda como "psicólogas escolares" (5\%).

\section{Instrumento de coleta de dados}

Nas entrevistas individuais, o instrumento utilizado foi um roteiro contendo questões para a caracterização do público alvo, por sexo, local de trabalho, o tempo que estáformado, tempo de atuação profissional, especializações, atividades profissionais realizadas concomitantemente à principal atividade e experiência profissional em instituições escolares.

Para caracterizar a atuação profissional das psicólogas, foram feitas questões que permitissem conhecer os seus objetivos, os instrumentais utilizados na avaliação e o trabalho realizado com crianças e adolescentes com queixas escolares.

Por fim, foi-lhes solicitada a descrição dos motivos do encaminhamento das crianças aos serviços de Psicologia do município, as causas atribuídas por esses profissionais às dificuldades escolares e o relato de suas dificuldades ao avaliar os resultados do seu trabalho, a fim de apreender as concepções que orientam a prática dos profissionais.

\section{Procedimentos de coleta e tratamento dos dados}

Foi realizado na Secretaria Municipal de Saúde de Ribeirão Preto (SP), um levantamento preliminar dos psicólogos que atuavam tanto em Centros de Saúde como em outros serviços públicos, oferecidos à comunidade desta cidade, que atendiam a esta demanda de crianças.

Utilizando um roteiro semi-estruturado, com questõeschave a serem abordadas mas acompanhando o discurso dos entrevistados, foram realizadas entrevistas individuais, gravadas e depois transcritas na íntegra. Os dados foram coletados por duplas de estudantes do curso de Psicologia, da Faculdade de Filosofia, Ciências e Letras de Ribeirão Preto da Universidade de São Paulo-USP.

A partir dos relatos das profissionais, estabeleceram-se classes temáticas de respostas para caracterizar a atuação dos profissionais, isto é, categorias de respostas que apontavam um mesmo significado no discurso dos entrevistados. Depois, verificaram-se as maiores incidências das respostas e montaram-se tabelas para melhor visualizar os temas existentes nas respostas dos psicólogos para comparar os resultados com outros estudos na área. Finalmente, foi feita uma análise qualitativa do discurso das psicólogas, a fim de apreender as idéias e as concepções que norteiam as atuações destasprofissionais.

\section{Resultados}

O levantamento dos casos de crianças e adolescentes encaminhados aos psicólogos permitiu verificar que a maior parte deles apresenta queixas relacionadas a questões escolares (69\%), confirmando que a atuação dos psicólogos nos serviços públicos de saúde está voltada para a resolução de problemas enfrentados na área da educação.

Nos $31 \%$ de queixas não associadas a questões escolares, encontraram-se problemas de enurese, encoprese, crianças vitimizadas por agressão ou abuso sexual, uso de drogas e doenças psicossomáticas ou psicopatológicas mais severas, como psicoses, depressão e ansiedade.

A Tabela 1 detalha as principais queixas escolares que motivaram os encaminhamentos, relatadas pelos psicólogos.

A soma das queixas apresentadas revela que $61 \%$ delas são relativas aos problemas de aprendizagem e de comportamento na escola. A natureza das queixas e a grande incidência de crianças encaminhadas apontam que as escolas ainda vêem o encaminhamento para o psicólogo como única forma de resolução dos problemas apresentados pelos alunos. Os psicólogos, por sua vez, acabam por reforçar esta compreensão, reafirmando que os problemas estão localizados nas crianças, como se pode verificar a partir dos relatos e dos dados obtidos na Tabela 2.

... o que acontece é que o problema escolar vem freqüentemente associado com problemas de comportamento, então tem aprendizagem e comportamento associados... e é difícil definir o que começa onde, mas assim a gente tenta trabalhar de forma que esta criança possa se adaptar melhor dos dois lados, tanto em termos do comportamento quanto na aprendizagem. Fora isso, as crianças pequenas vêm com queixa de enurese, problemas de alimentação, problemas psicossomáticos... (sujeito 1 )

Muitos casos são por comportamento... e a maioria por falta de atenção... e aí acho que uma coisa leva a outra. Se não me comporto bem, eu não presto atenção, se eu não presto atenção, como vou aprender? (sujeito 5)

Metade das respostas (53\%) emitidas por estes psicólogos localizam as causas das dificuldades escolares ou no meio social ou no próprio aluno. Nos depoimentos a seguir é possível verificar que, na visão destes profissionais, ainda são a criança pobre, sua família e suas condições de vida as grandes responsáveis pelas dificuldades escolares. Responsabilizam a desestruturação familiar, a falta de apoio dos pais, o desinteresse destes pela vida escolar de seus filhos, a falta de estimulação em casa para o estudo. Porém, estas concepções não são decorrentes do conhecimento destas crianças no contexto familiar e de suas famílias, como se verá mais à frente, uma vez que tais idéias não provêm de um contato mais intenso e sistemático com a realidade desta clientela. 
Tabela 1

Freqüência e porcentagem das queixas escolares que motivam o encaminhamento de crianças atendimento psicológico

\begin{tabular}{|c|c|c|}
\hline Queixas escolares que motivam o encaminhamento das crianças & $\mathrm{N}^{*}$ & $\% * *$ \\
\hline $\begin{array}{l}\text { Problemas de aprendizagem - crianças que não acompanham o ittmo da sala de aula, } \\
\text { não aprendem, têm lentidão para aprender, dificuldade na alfabetização, falta de } \\
\text { atenção e de concentração, problemas psicomotores }\end{array}$ & 20 & 31 \\
\hline Problemas de comportamentos - indisciplina, agressividade ou hiperatividade & 19 & 30 \\
\hline $\begin{array}{l}\text { Problemas emocionais - inadaptação, fobia escolar, experiências negativas na escola, } \\
\text { problemas de relacionamento com a professora ou com outras crianças, insegurança ou } \\
\text { timidez }\end{array}$ & 11 & 18 \\
\hline $\begin{array}{l}\text { Outros relacionados a questões escolares - problema de fala, gagueira, problemas } \\
\text { familiares, separação dos pais, drogas em casa ou doenças dos pais }\end{array}$ & 8 & 13 \\
\hline Deficiência Mental & 3 & 5 \\
\hline Encaminhamento para a classe especial & 2 & 3 \\
\hline Total & 63 & 100 \\
\hline
\end{tabular}

... a questão assim, crucial que acaba influenciando aí o desenvolvimento das crianças... são os pais, que não têm nível de instrução e que não podem proporcionar a essas crianças uma estimulação fora da escola... (sujeito 1)

A meu ver, as principais causas são de caráter social, atualmente abrangendo todas as classes; o desemprego, falta de infra-estrutura, falta de comida, a alimentação é deficiente, os pais não sabem como lidar com seus filhos, cobram muito e não cobram nada, os pais não conseguem colocar limites para os filhos, têm dó da criança. Também a criança falta da escola porque não tem dinheiro para o ônibus, também problemas na família, doença na família, mães doentes mentais, pais alcoólatras, separação dos pais... (sujeito 4)

... crianças que vêm aqui com a dificuldade de aprendizagem são crianças que estão com problemas emocionais também, ou relativo à própria dificuldade de aprendizagem, porque eu vejo a dificuldade de aprendizagem uma pontinha lá de alguma coisa que não está bem e que está refletindo...ou a estrutura familiar, ou a organização interna da criança comprometida, ou é a relação com a escola que não está bem, ou é um atraso mesmo da criança, que a criança tem. Então a dificuldade de aprendizagem está ligada num monte de coisas. (sujeito 7)

Mas é possível verificar também que a escola e seus problemas internos estão presentes nas análises críticas de alguns destes profissionais. Para eles, a escola também contribui para as dificuldades das crianças devido à sua falta de infra-estrutura, às mudanças constantes no sistema educacional e à sobrecarga de trabalho dos professores (17\%). Referem ainda que o modo de atuar da escola, isto é, a existência de classes numerosas, do preconceito com que é vista a criança de classes populares e do descompromisso para com ela, dificulta aos professores dar uma melhor atenção aos alunos.

A escola está com dificuldade de manejar os fatores adversos da própria escola, né, o número excessivo de alunos, a escola sem muitas condições materiais, a escola sem professor preparado.... a escola não está preparada pr' a receber a criança com dificuldade de aprendizagem. (sujeito 8)

Bom, aí é a parte da família... agora, relacionado à escola, está (sic) as próprias mudanças ocorridas na área da educação e que eu acho que as crianças que estão passando

Tabela 2

Freqüências e porcentagens das causas atribuídas pelos psicólogos às dificuldades escolares

\begin{tabular}{lcc}
\hline Causas das dificuldades escolares & $\mathrm{N}^{*}$ & $\%^{* *}$ \\
\hline Meio social do aluno & 38 & 31 \\
Aluno & 28 & 22 \\
Escola e o sistema educacional & 21 & 17 \\
Modo de atuar da escola em relação ao aluno & 21 & 17 \\
Corpo docente, técnico e administrativo & 15 & 12 \\
Escola na sua função político-social & 1 & 1 \\
Total & 124 & 100 \\
\hline
\end{tabular}

* Número de vezes que cada causa das dificuldades escolares são apontadas pelos psicólogos.

** Porcentagem sobre o total de causas mencionadas pelo grupo de psicólogos. 
agora pela escola estão sofrendo demais, porque elas estão pegando todas essas mudanças e estão até mesmo cobaias, né, porque o professor ainda está buscando uma nova forma de atuar com a criança. E então, eu acho que é um período difícil... (sujeito 12)

... são muitas né ,... mas muitas é a forma que a escola está lidando com a criança, né,... já rotula, acha que aquela criança já não vai, não melhora, não adianta, acham que já fizeram tudo... (sujeito 13)

... depois da questão social, eu vejo a questão da escola, que realmente quer que o aluno se adeqüe (sic) a ela e ela não se adequa (sic) ao aluno, né, e tem o número de alunos por classe que é absurdo, e o professor está sobrecarregado demais, ele não tem auxílio, são classes enormes e não tem um auxiliar ali com ele... Francamente, eu acho muito lindo o que se fala e as mudanças, mas na prática eu achei que culminou num... e, tudo o que já está acontecendo aqui, e aí agora essa mudança de adequar a idade, eu nem sei como chama, eu esqueci... de colocar a criança na idade , né, no grupo de idade que ela freqüenta. A criança de 11 ano foi colocada na $5^{\mathrm{a}}$ série sem saber sequer ler ou escrever, e as classes ficaram muito heterogêneas, muito grandes, e assim não vejo uma saída para isso, e aí vai acabar em violência, muita agressividade... (sujeito 14)

Os professores e o corpo técnico e administrativo (12\%) também são mencionados pelos psicólogos como causadores das dificuldades escolares dos alunos.

... há falta de recursos materiais e físicos, o governo não ajuda, mas o professor precisa ser mais criativo, procurar trabalhar mais com a criança. Ela acaba ficando sem estímulo para o processo de aprender. (sujeito 15)

Ainda que alguns profissionais mencionem a existência de problemas internos da escola, mostrando algumas práticas educacionais inadequadas, não chegam a formular uma análise mais abrangente das questões em jogo que permita perceber a participação da instituição-através das suas relações, concepções e práticas - na produção das dificuldades escolares das crianças.

Apenas alguns poucos psicólogos apresentam uma compreensão mais abrangente destas dificuldades, focalizando também os problemas da escola na sua função político-social que mantém em suas relações, mecanismos de dominação e discriminação de uma classe menos favorecida e que estigmatiza as crianças como menos aptas.

... e não acredito que seja só um problema da criança porque acontece muitas vezes aqui que alunos de uma mesma sala são encaminhados. Então você começa a perceber muita semelhança e aí você começa a suspeitar: será que esse problema é da forma que a professora está ensinando, ou é só atribuir a culpa na criança, no aluno? Então, é preciso fazer uma análise da família, da escola como um todo. (sujeito 2)
... A questão da própria escola que não altera os métodos...ela até tem propostas e tal, mas não muda a cabeça do professor, não vai investir no professor para que ele se atualize. Então fica (sic) aulas maçantes e chatas, né? ... Ah! O desconhecimento do professor do processo de aprender, porque o professor não sabe como a criança aprende.... então, ele avalia, e ele discrimina, ele não valoriza o que a criança traz, né, do seu meio cultural. Então, tudo isso contribui para as dificuldades". (...) A mais importante, eu acho que é difícil falar do fracasso escolar sem ter uma parcela da própria escola. A escola fica num jogo de empurra para a saúde, para a família, a culpa é do pai, da mãe, porque os pais se separaram, porque isso e porque aquilo... também é do psicólogo que não quis atender minha criança, é o médico que não deu remédio, a fono que não falou o que é que tinha que fazer, e não tinham a sua parcela. Se eles entendessem a sua parcela de investimento no fracasso escolar... e eu entendo as dificuldades que existe (sic), todo um sufocamento destes profissionais aí, e eu não estou julgando ninguém. Acho que não ser ouvido por ninguém e ser jogado uma política por cima da sua cabeça e falar "Olha, faça isso: a partir de hoje não tem mais reprovação, a partir de hoje você não vai poder colocar zero para seu aluno". É difícil. Então eu acho que a escola..., mas não enquanto professor, diretor, né, mas a escola como um todo, como uma função política e social. (sujeito 11)

Os modos de atuação, como se verá a seguir, mostramse, então, em consonância com as concepções que orientam a percepção desses profissionais dos problemas a serem trabalhados com as crianças.

A Tabela 3 demonstra que $94 \%$ dos psicólogos utilizam os testes psicodiagnósticos como medida de avaliação das supostas capacidades individuais das crianças, ainda que esses mesmos profissionais façam críticas a estes instrumentos quanto à sua possibilidade de caracterizar os problemas e potencialidades dos alunos. Também se observa que $63 \%$ deles buscam complementar as informações desta avaliação com o uso das anamneses, procurando assim identificar na família ou nos dados de saúde da criança as possíveis causas dos problemas escolares apresentados. O segmento a seguir ilustra essa afirmação.

Como a criança vem de uma queixa específica da dificuldade de aprendizagem, tá, eu costumo começar sempre com uma avaliação, de como é que tá essa criança, e aí, eu utilizo teste...e também eu observo essa criança no jogo, em atividades pedagógicas, como ela se sai, para decidir que caminho tomar e para ver que outras dificuldades a criança apresenta, onde estão as falhas que possam estar interferindo na aprendizagem ....Detectando alguma coisa nesse sentido, ou às vezes alguma falha em termos de processos cognitivos básicos ou então em termos de alguma defasagem psicopedagógica, eu faço um planejamento de um trabalho psicopedagógico. E em geral, eu vou estar tentando ver então, a partir da história que eu coleto dos pais..., 
na verdade eu sempre começo pela anamnese, né, pela história com os pais (...) em geral eu pego a história da criança, o que está acontecendo, se essa criança já vinha com história de problemas relacionado a problemas de comportamento, que possam estar interferindo na escola... Também vejo se tem alguma coisa que está ligada ao relacionamento dela dentro da escola, e a partir dessa primeira avaliação é que planejo então o trabalho, seja o trabalho que eu vá ter uma atuação mais psicopedagógica, ou um trabalho que eu vá ter mais um atendimento clínico (...) de tempos em tempos também solicito a presença dos pais (...) porque eu acredito que se a família não apóia, o tempo que eu tenho não adianta muito. (sujeito 1)

No que diz respeito à atuação do profissional psicólogo, as orientações por eles referidas tomam duas direções: 0 "atendimento psicopedagógico" a a "ludoterapia”. O “atendimento psicopedagógico", segundo a descrição dos profissionais consiste em atividades que têm o objetivo de desenvolver habilidades que favorecem o processo de aprendizagem como atividades de leitura, interpretação de texto, jogos para desenvolver raciocínio, memória, percepção, atenção, discriminação visual, habilidades psicomotoras e cognitivas, para desenvolver o pensamento lógico. Inclui-se ainda a discussão de temas que procurem desenvolver habilidades sociais para a convivência social. Já o "atendimento ludoterápico" é utilizado com o objetivo de resgatar a autoestima, promover na criança uma relação prazerosa com a aprendizagem e com a escola, além de ajudar a melhorar seu relacionamento em classe. Os psicólogos caracterizamna por atividades lúdicas, de dramatização, brincadeiras, expressão gráfica, trabalhos de artesanato, música, relaxamento, meditação, técnicas comportamentais ou psicodramáticas, bate-papo ou conversas sobre as dificuldades que a criança apresenta ou sobre os fatos que ocorrem na escola, sempre visando trabalhar os sentimentos da criança frente às situações vivenciadas.

Embora declarem uma preferência pelas atividades lúdicas no atendimento das queixas escolares, os dados revelam que $42 \%$ dos profissionais realizam essas atividades junto com as atividades psicopedagógicas $(2+4)$. A escolha por estas duas técnicas de atendimento revela uma preocupação voltada para a ação prática, com objetivo de adaptar a criança a comportamentos esperados pela escola. No entanto, quando atuam desta forma, parecem desconsiderar as fundamentações teóricas específicas de cada modelo de atuação, mostrando uma confusão ao mesclarem diversas abordagens sem levar em consideração os aspectos contraditórios presentes nelas.

Outro trabalho utilizado é o de orientação de pais, realizado por $52 \%$ dos psicólogos, o qual tem por objetivo, segundo as declarações feitas, promover em casa o desenvolvimento dos comportamentos esperados para o bom desempenho escolar das crianças. Visa a orientar os pais quanto à

Tabela 3

Freqüência e porcentagem dos psicólogos no trabalho que realizam

\begin{tabular}{lcc}
\hline Trabalho realizado pelos psicólogos & $\mathrm{N}$ & $\%$ \\
\hline 1. Avaliação psicodiagnóstica (uso de testes) & 18 & 94 \\
2. Atendimento ludoterápico & 14 & 74 \\
3. Entrevista de Anamnese & 12 & 63 \\
4. Atendimento psicopedagógico & 11 & 58 \\
5. Orientação de pais & 10 & 52 \\
6. Não atuam (realizam triagem e encaminhamentos para & 9 & 47 \\
psicólogos) & & \\
7. Encaminhamentos para outras áreas da saúde & 8 & 42 \\
8. Entrevista com professora & 7 & 37 \\
9. Inscrição e triagem & 6 & 32 \\
10. Relatórios/Planejamento/ Devolutiva & 6 & 32 \\
11. Reunião equipe multiprofissional * & 3 & 16 \\
12. Avaliação sem uso de testes & 2 & 10 \\
Associação de áreas de trabalho & & \\
1+ 3 & 12 & 63 \\
2+ 4 & 8 & 42 \\
$1+2+3$ & 8 & 42 \\
\hline * Parte do projeto realizado pela Secretaria Municipal de Saúde da Ribeirão Preto, para atender à demanda de crianças e \\
adolescentes com as aueixas escolares.
\end{tabular}


"necessidade de colocação de limites, de sua participação na escola e nas atividades escolares das crianças", buscando estimulá-las na realização das tarefas e equacionar os problemas de relacionamento familiar.

\begin{abstract}
... tem um projeto Escola de Pais, que chama "Como ajudar seu filho na escola" e são dadas cinco aulas aos pais, onde a gente esclarece a eles as dificuldades de aprendizagem e alguns manejos em casa, que podem estar proporcionando uma melhor aprendizagem ou facilitando a aprendizagem da criança. São cinco aulas e os pais que freqüentam o curso recebem um certificado, como um curso, né? Têm que se inscrever e tal (...) porque os pais assim, não é que eles não queiram fazer, mas às vezes eles não se sentem competentes e esse curso tem como objetivo a gente estar mostrando aos pais o que eles podem fazer, que eles são competentes e que mesmo não sabendo ler e escrever, eles podem ajudar o seu filho em casa em vários aspectos. São atitudes muito simples como passos que a gente ensina a eles como fazer em casa para estar proporcionando a eles melhor aprendizagem, aprendizagem prá vida, melhor percepção do social, do auto-conceito, da auto- estima.. Então, a gente trabalha isso. (sujeito 8)
\end{abstract}

Em suma, é possível verificar, com essas respostas, que os psicólogos acreditam que, ao ensinarem os pais a cuidar dos seus filhos, levando-os a assumir sua responsabilidade pela prole, terão assim equacionado os problemas escolares das crianças. Nesta atuação, parecem partir do pressuposto de que os pais não sabem educar seus filhos de maneira adequada, não os preparando para o processo educativo.

O contato deles com a escola também se dá esporadicamente, buscando com a professora informações que confirmem o diagnóstico dos problemas de aprendizagem ou comportamento e que justifiquem o encaminhamento das crianças, como revelam $37 \%$ dos psicólogos entrevistados.

... às vezes, observo a criança na escola e converso com o professor para saber como essa criança funciona na escola, que queixa veio da escola, e hoje em dia, às vezes, o professor consegue perceber mais que alguns pais e mães. Então, é importante você ter esse contato... (sujeito 2)
Um outro dado relevante nas respostas emitidas é que estes profissionais contam com uma estrutura de trabalho para acompanhar os atendimentos, procurando dar qualidade àquilo a que se propuseram realizar: têm reuniões semanais ou quinzenais com a equipe multiprofissional (16\%), discutem os casos apresentados pela escola e fazem encaminhamentos para as outras áreas da saúde (42\%), como fonoaudiologia, oftalmologia, psiquiatria, terapia ocupacional e serviço social. Também elaboram relatórios, planejam o trabalho, organizam as devolutivas para os pais ou professores quando estes solicitam (32\%), fazem inscrição e triagem (32\%). Em alguns serviços contam também com psicólogos voltados exclusivamente à triagem e ao psicodiagnóstico (10\%) para posteriormente encaminhar as crianças ao atendimento ludoterápico ou psicopedagógico.

Sentindo-se apoiados por um serviço estruturado, a avaliação dos profissionais acerca do trabalho que realizam é positiva, como se pode constatar pela Tabela 4 .

As dificuldades do trabalho realizado, apontadas por grande parte deles, surgem entretanto, atreladas a causas externas, decorrentes da existência de problemas "que fogem da sua alçada e da possibilidade de resolvê-los" (47\%), tais como, "a desistência da família ao tratamento, o desinteresse dos pais, os problemas de aprendizagem que estão associados a problemáticas familiares que não se resolvem, a falta de colaboração da família e da escola e à existência de dificuldades escolares que estão associadas a comprometimentos psicopatológicos mais severos".

Compartilhando da crença disseminada de que as famílias não têm interesse pelas crianças, nem pelo tratamento e que os problemas vividos por elas ou deixaram marcas irreversíveis no seu desenvolvimento ou são problemas familiares estruturais, esses profissionais não chegam a questionar as razões pelas quais os pais desistem do tratamento, nem a buscar, no próprio trabalho realizado, os motivos da desistência. Assim, uma visão parcial da problemática vivida por essas crianças e seus pais, culpando a família, inviabiliza a percepção de outros fatores em jogo na desistência: a discordância dos pais sobre o motivo da queixa escolar, de-

Tabela 4

Freqüência e porcentagem das respostas dos psicólogos referentes à avaliação do trabalho realizado

\begin{tabular}{lcc}
\multicolumn{1}{c}{ Avaliação do trabalho } & N & $\%$ \\
\hline Os resultados do trabalho são positivos, mas há os problemas que fogem à & 9 & 47 \\
sua alçada, não havendo possibilidade de resolvê-los & & 53 \\
Críticas à infra-estrutura oferecida para o desenvolvimento do trabalho & 10 & 53 \\
Críticas à proposta de atendimento psicológico, do ponto de vista conceitual & 5 & 26 \\
e metodológico & 5 & 26 \\
Avaliação positiva da proposta de atendimento psicopedagógico e/ou clínico & 5 & 2 \\
\hline
\end{tabular}


correntes da ausência de professor durante grande parte do ano letivo, dos remanejamentos constantes da criança de série ou de classe que contribuíram para a desistência dela das coisas da escola, o encaminhamento dos "indesejados" para a classe especial etc. Está ausente dessas análises a compreensão de que a queixa escolar que motiva a quase totalidade dos encaminhamentos é produzida na escola e na medida em que essa dimensão não é analisada, os problemas são tratados como casos "crônicos da criança".

Os resultados têm sido positivos, a não ser nos casos mais graves, que eu não tenho formação para atender aqueles casos patológicos. (sujeito 4 )

Olha, eu tenho tido boa resolutividade dos casos sim, mas o que acontece em posto de saúde é uma grande rotatividade (...) tem outros casos que tem uma psicopatologia mais grave, a família tem todo um funcionamento diferenciado, um funcionamento também bastante perturbado. Além disso, essa família não tem condições financeiras prá estar modificando a estrutura da casa, prá estar apoiando melhor as crianças, e nossa área não tem um equipamento social prá onde a gente possa estar encaminhando essas crianças mais velhas (...). (Sujeito1)

As críticas surgem também, para 53\% dos psicólogos, em relação à precária infra-estrutura oferecida para o desenvolvimento do trabalho, dando destaque ao pouco tempo de atendimento com a criança, à dificuldade de realizar um trabalho individual mais aprofundado, à grande demanda, à falta de recursos como sala, material adequado, falta de incentivo e investimento para que os psicólogos se aperfeiçoem.

Há resolutividade, o único problema é que o sistema não suporta a demanda que é alta. (Sujeito 3)

Acredito nesse trabalho, penso que em termos de eficácia na resolução dos problemas escolares ele alcança os objetivos, entretanto, devido ao pouco tempo de atendimento, que é semanalmente com duração de uma hora, é um trabalho lento. (sujeito 10)

Você tem muitas pressões, por exemplo, para ser um atendimento rápido, para que não haja lista de espera, pressões que você tem que resolver o caso da família... Então existe essa expectativa (...) Tem dificuldades por exemplo, você vai montar um grupo, você as vezes não tem nem cadeira. Como a gente vai montar um grupo, se a gente não tem nem material adequado? Então, eu acho que falta(sic) recursos. Você atende cada dia numa sala, minha sala é bem do médico, então a criança entra... tem salas que tem essa macas, mas tem salas que tem aquelas macas ginecológicas e a criança entre e logo pergunta prá que serve aquilo, então no início fica confuso. Você não tem um armário, então fica carregando o material de um lado para o outro. ( sujeito13)
Por outro lado, encontramos alguns psicólogos (26\%) que, se não apresentam ainda uma visão teórica da complexidade da problemática da escola pública e suas determinações sobre o desempenho escolar das crianças, têm críticas conceituais e metodológicas à proposta de atendimento psicológico, uma vez que o trabalho desenvolvido não resolve o problema na escola, "pois o trabalho é mais pontual sobre a criança, e assim trabalha-se com a consequiência do problema gerado na escola e não diretamente com os problemas escolares". Pode-se ver que as dúvidas sobre a eficácia de um tratamento que centre seu atendimento apenas na criança pobre, estão lançadas para alguns destes psicólogos que chegam a criticar o pouco investimento na família, na escola e no trabalho junto aos professores.

Eu acho que é muito pontual ainda. Eu acho que quando a gente trabalha numa unidade de saúde, no meu ponto de vista, você trabalha para ajudar a saúde mental da criança, tá? Melhorando a auto-estima, fazendo com que elas percebam as potencialidades delas, trabalhando o vínculo da família, né? Eu acho que é mais por aí. Eu não sei se isso resolve o problema da escola, é que eu acho que eu trabalho mais o problema criado pela escola, pois se a escola fosse eficaz, se ela despertasse o desejo de aprender do aluno, se ela motivasse os seus alunos, eu acho que a minha demanda seria menor, e a gente trabalharia com questões mais específicas, mas isso não acontece. Então, eu não resolvo problema da escola, eu resolvo o problema daquela família, daquela criança, no seu contexto social, afetivo. Eu busco que ela se desenvolva como um ser humano mais saudável do ponto de vista da saúde mental. (sujeito 11)

Tem dado resultado, sim. Tenho tido um bom retorno através do trabalho, tanto em termos da escola, quanto em termos de evolução da criança, já dando resultado. (sujeito 15)

Considero meu trabalho bom, tenho obtido bons resultado e as crianças atingem melhoras escolares e de convivência social. (sujeito 16)

Percebe-se que a visão da problemática escolar das crianças caracteriza-se pela dicotomia entre o emocional e o cognitivo. Estes profissionais parecem acreditar que trabalhar com a auto-estima da criança através de atividades lúdicas é condição suficiente para a solução do desinteresse das crianças pela escola, sem que o problema escolar gerador do desinteresse (p. ex. atividades pedagógicas sem sentido, praticas escolares produtoras de dificuldades para a compreensão das tarefas propostas etc.) seja, para a maioria deles, também alvo de análise e intervenção. Do mesmo modo, quando a queixa identifica problemas na aprendizagem dos conteúdos escolares, pressupõe-se que o desenvolvimento de habilidades psicomotoras, de habilidades cognitivas, favorecendo o pensamento lógico, garantirá a aprendizagem da matemática, da língua escrita, desconsiderando 
as críticas produzidas a este respeito pela teoria construtivista de alfabetização (Ferreiro \& Teberosky, 1991).

\section{Discussão}

Ao caracterizar as concepções que orientam as formas de atuação profissional dos psicólogos que atendem à demanda de crianças encaminhadas com queixas escolares aos serviços públicos e instituições não-governamentais em Ribeirão Preto-SP, algumas reflexões devem ser feitas a respeito de como tem sido tratada a questão dos problemas escolares e qual tem sido o papel da psicologia nesta área.

Os resultados mostraram que a compreensão que ainda se tem da queixa escolar, por grande parte dos psicólogos, é que esta advém de um problema individual, pertencente à criança encaminhada e entendido, na maioria das vezes, como de âmbito emocional ou cognitivo, decorrente das supostas conseqüências das suas condições de vida sobre o seu desempenho escolar. Assim, acreditam que ao desenvolverem um trabalho dirigido à compensação de supostas defasagens cognitivas, à eliminação de comportamentos inadequados e ao tratamento de supostos problemas emocionais, podem eliminar os problemas escolares. Dessa forma, as práticas de avaliação e trabalho psicopedagógico são coerentes com esta compreensão, como se o funcionamento psíquico e os processos mentais envolvidos na aprendizagem acadêmica da criança pudessem ser entendidos e trabalhados de forma independente da análise do contexto institucional onde os problemas escolares são produzidos.

Embora a literatura aponte o quanto a psicologia vem nas últimas décadas questionando sua atuação profissional, buscando outros caminhos para o entendimento dos problemas escolares das crianças e adolescentes de classes populares e produzindo uma revisão crítica das formas de análise da criança pobre e suas condições de vida como a única responsável pelo seu fracasso escolar, ainda assim uma boa parte dos psicólogos utiliza estes referenciais teórico-metodológicos para trabalhar com as queixas escolares.

Muitos estudos vêm revelando que as dificuldades escolares são produzidas pelas práticas, crenças e pelas redes de relações ocorridas no interior da instituição escolar (Carraher, 1982; Collares \& Moyses, 1996; Patto, 1990; Souza, 1993), mas elas não se fazem ainda suficientemente presente nas concepções dos psicólogos pesquisados, e consequentemente não se buscam formas alternativas de atuação profissional. Observa-se que nem mesmo os avanços já obtidos na área clínica que integram o social e o psíquico e não concebem a criança separada do contexto social e escolar, (Bleger, 1985; 1992; Boarini \& Borges, 1998; Bohoslavsky, 1997; Costa, 1984; Freller,1997; Kupfer, 1992; Moffat, 1984), têm sido incorporados aos discursos desses profissionais.

Por outro lado, os psicólogos demonstram a necessidade de entrar em contato com a realidade escolar, mas nota- se que seu preparo profissional, apesar do alto nível de qualificação acadêmica, não lhes forneceu os elementos necessários a uma compreensão psicossocial da dinâmica escolar capaz de analisar a escola como uma instituição feita de sujeitos sociais (professores, alunos, equipe técnica e pais), os quais se relacionam entre si e dirigem as concepções que orientam as práticas educativas e seus resultados. Emoutras palavras, não aparecem em seus relatos, para a grande maioria deles, uma visão mais abrangente dos problemas escolares como decorrentes de concepções e práticas educacionais produtoras de dificuldades de aprendizagem.

Um trabalho de intervenção institucional que vem sendo realizado desde 1995 por alguns alunos de graduação em psicologia escolar da Faculdade de Filosofia, Ciências e Letras da USP, junto a algumas escolas de Ribeirão Preto (Pioto et al., 1997) vem confirmando a existência de diversos fatores intra-escolares na produção das dificuldades de aprendizagem das crianças e a necessidade de um trabalho do psicólogo voltado à analise das relações interpessoais e intersubjetivas que são produzidas na instituição educacional.

No referido trabalho, observou-se que a crença da escola, também presente na visão de muitos psicólogos, de que as dificuldades em aprender se localizam nas crianças, tem levado a grande maioria destas às classes especiais para deficientes mentais, gerando indisciplina, comportamentos de apatia, indisposição para as coisas da escola, abandono da escola. E mais, tem contaminado negativamente a visão de muitos professores sobre a sua capacidade de escolarizar essas crianças tidas como deficientes.

As práticas de remanejamento de classe e de série, durante todo o ano letivo, ainda são uma constante na escola, sem que se analise as suas consequiências sobre os comportamentos das crianças na escola e no seu rendimento escolar. Muitas das queixas escolares que justificaram os encaminhamentos para os psicólogos, como a da falta de "raciocínio lógico e abstrato para assimilar as contas de matemática" não se confirmam, quando um contato prolongado com essas crianças na escola, revelam-nas capazes de elaborar contas "de cabeça" em jogos e brincadeiras. Também o remanejamento quatro, cinco vezes durante o ano para classes, séries e professoras diferentes, inviabilizou a aprendizagem dos mecanismos de elaboração da "conta armada" que exige a compreensão da base decimal - centena, dezena e unidade.

O pressuposto de que a criança vai mal na escola porque é proveniente de família desestruturada ou porque há desinteresse da família pela escola não se confirma a partir de um trabalho do psicólogo, com os professores, as próprias crianças e suas familias, de resgate da história familiar e escolar. No entanto, essa percepção equivocada, baseada em preconceitos em relação às famílias pobres, culpando os pais pelas dificuldades escolares das crianças, têm definido as relações entre a escola e as famílias, levando-as ao não com- 
parecimento às reuniões de pais e, em alguns casos, gerando conflitos entre pais e professores, bem como vem criando um aumento da agressão dos pais para com as crianças. Estes aspectos todos, analisados a partir do contexto escolar, permitem perceber como as queixas de indisciplina, agressividade das crianças, apatia, falta de atenção estão diretamente relacionadas a esses episódios.

A soma de fatores como os baixos resultados obtidos muitas vezes pelas crianças de classes populares nos testes psicodignósticos, a culpabilização das famílias e mais recentemente a culpa depositada no professor - cada vez mais alvo de preconceitos, sem que as suas condições de trabalho e os seus baixos salários sejam também considerados - têm levado muitos professores a desistir de ensinar e recorrendo aos preconceitos, encaminham estas crianças para os serviços de atendimento psicológico, na esperança de que eles poderão resolver a situação.

Nas respostas dos psicólogos nota-se que há uma percepção das dificuldades por que passa a escola pública, mas, via de regra, a análise localiza-se em aspectos parciais da problemática escolar: na má formação dos professores, nas classes numerosas, no despreparo do profissional para lidar com sua clientela, nas dificuldades materiais e técnicas para os professores executarem seus trabalhos.

Isto sugere a falta de uma visão mais crítica que incorpore a compreensão da problemática escolar a partir de um novo modo de olhar a instituição, no qual se atente não só à criança, mas também no modo de a escola se relacionar com sua clientela, suas concepções e suas práticas internas como processos psicossocias. Em outras palavras, os psicólogos precisam olhar para as relações, concepções e práticas escolares que fazem parte de um quadro social, político e econômico mais amplo, presente na subjetividade dos indivíduos que fazem a escola e que, por serem determinantes dos resultados escolares das crianças, devem ser objeto de investigação e intervenção da psicologia.

Mas para que os psicológos incorporem essa nova visão da problemática escolar, eles precisam partir de um referencial teórico-metodológico que compreenda o aluno e o professor como personagens envolvidos no conjunto de relações e sentidos que se estabelecem no interior da escola e na relação desta com sua clientela (Patto, 1985; Ezpeleta \& Rockwell, 1989; Machado \& Souza, 1997). Ao revelarem outras compreensões das queixas escolares, estes estudos têm permitido uma redefinição das formas de atuação da psicologia nestas queixas. Eles vêm apontando a necessidade de uma revisão dos instrumentais de avaliação psicodiagnóstica, que, baseados em visões limitadas da inteligência humana, não têm seus resultados confirmados quando o aluno é investigado em outros contextos que não o consultório ou a escola ou a partir de questões que meçam o seu conhecimento escolar.
Dentro desta nova visão, o foco da intervenção parte de uma escuta orientada para se compreender as queixas escolares, levando o psicólogo a analisar os relatos dos professores, pais, crianças, equipe técnica e as circunstâncias que envolvem os vários protagonistas presentes no processo de escolarização.

O trabalho de intervenção envolve vários aspectos da realidade escolar como a qualidade da relação professor-aluno em sala de aula, as formas de transmissão dos conteúdos pedagógicos e as situações de ensino-aprendizagem propostas em classe, os vínculos existentes entre o professor e as famílias, a história pessoal e escolar da criança e como a escola e o professor se apropriaram dela, a definição de critérios para a seleção do aluno por classe e por professor, a concepção de disciplina pelos professores e pela instituição e as formas pelas quais as normas disciplinares definem as relações da instituição com seus alunos, as concepções que a instituição possui de sua clientela e de suas capacidades de aprendizagem.

Sabe-se que a qualidade da relação professor-aluno é determinante do processo ensino-aprendizagem, não só em seus aspectos cognitivos, mas também psicossociais. No cotidiano escolar, tem-se observado que a avaliação que os professores fazem dos alunos está permeada por uma visão preconceituosa que, tomando-os como incapazes - muitas vezes ratificados pelo psicodiagnóstico - relega a segundo plano as situações de aprendizagem e a transmissão de conteúdos escolares, produzindo dificuldades escolares para o aluno. Nesta postura, justificam o encaminhamento para os psicólogos (Patto, 1990).

Outro aspecto que chama a atenção é a indisciplina, que vêm sendo apontada como uma das maiores queixas da escola em relação aos alunos. Quando analisada no contexto em que surge, ela revela-se portadora de múltiplos significados e sintoma de vários conflitos presentes na escola, como a revolta gerada pelo encaminhamento para a classe especial, tida em muitas escolas como lugar de punição para onde vão aqueles que ninguém quer, tornando o aluno alvo de agressão dos outros colegas. As próprias normas disciplinares muito rígidas (como atitudes de suspensões, encaminhamentos para o conselho tutelar ou até mesmo para a delegacia) acabam gerando conflitos, pois havendo um aumento da violência dos pais contra os filhos que tiveram advertências na escola, muito provavelmente esta retorna para a escola sob a forma de comportamentos violentos do aluno com o professor e os colegas. Também a falta de regras claras da própria escola em relação aos alunos e aos professores cria relações interpessoais baseadas na arbitrariedade, no autoritarismo, no privilégio de interesses particulares, e geram revolta pelas injustiças cometidas.

Outra fonte de conflitos e revolta, que gera indisciplina, são as agressões baseadas em preconceitos contra o pobre, 
o negro e a mulher, presentes nas relações das crianças entre si e com a professora, o que interfere diretamente no desempenho escolar das crianças e nas possibilidades de ensino do professor.

Enfim, todos estes aspectos não podem mais passar despercebidos pelos psicólogos que atuam na queixa escolar e não podem ser ignorados em sua prática profissional.

É conhecida a precariedade dos cursos de psicologia e sua parcela de responsabilidade na formação dos profissionais que atuarão nestas queixas, seja pela quase ausência de críticas à compreensão de que a criança pobre e sua família são responsáveis pelo fracasso escolar, seja pela visão parcial com que analisam a escola oferecida a estas crianças (Souza, 1996).

A forte influência de uma visão médico-hospitalar na psicologia (Pessotti, 1975) deixou também raízes profundas na formação dos psicólogos e na maneira de compreender as contribuições da psicologia no processo educacional. Esta visão imprimiu na ação dos psicólogos uma linha nitidamente clínica, norteada sobretudo por atuações diagnósticas e curativas, nas quais predomina um atendimento psicoterapêutico individualizado ao aprendiz com queixa escolar, visto como portador de características pessoais incompatíveis com a aprendizagem e o ajustamento escolar.

Nesse contexto, pode-se entender as dúvidas e confusões destes psicólogos quanto às concepções de que dispõem no seu exercício profissional, apontadas em vários momentos de seus depoimentos pois, ao não incorporarem uma análise mais ampla sobre a compreensão da queixa escolar, não buscam um referencial teórico-metodológico que dê conta de entender o que se passa na realidade das escolas públicas no Brasil.

Além do mais, faz-se necessária uma revisão dos instrumentais de avaliação psicodiagnóstica das crianças, para que eles permitam o conhecimento da realidade escolar na qual a criança está inserida, já que as relações também são determinantes das respostas das crianças aos testes. É preciso que os instrumentais de avaliação consigam expressar como os vários protagonistas compreendem os fatos e processos escolares vividos e que sentidos atribuem a eles no contexto escolar.

As contribuições trazidas pela psicologia institucional, tal como proposta por Bleger (1992), e as mudanças nas maneiras de compreender as queixas escolares (Machado, Sayão \& Souza, 1997; Machado \& Souza, 1996; Patto, 1990; Sawaya, 1999) vêm apontando caminhos para um trabalho na escola, seja na vertente dos grupos operativos de Bleger, seja através das contribuições com base em Winnicott , seja ainda nas contribuições de Lacan pela análise da "circulação discursiva" que se dá na escola. Estas perspectivas teórico-práticas vêm fornecendo ao psicólogo embasamento teórico para auxiliar o professor a repensar a sua prática docente, os objetivos da escola, as formas da escola perceber o aluno e se relacionar com ele.

\section{Conclusão}

O presente estudo vem confirmar que as concepções dos psicólogos sobre as causas das queixas escolares das crianças de camadas populares e a sua ação são indissociáveis. Em outras palavras, vimos que são as concepções de que eles dispõem que orientam a sua ação profissional. Este trabalho aponta a necessidade de se rever o papel do psicólogo que atua junto às crianças portadoras de queixa escolar, o qual deve incluir, em sua atuação profissional, a análise e a intervenção na instituição escolar. Acreditamos que a solução para a mudança da postura do psicólogo não se encontra na inovação técnica que passe a produzir maiores índices de "cura" (definida em termos da integração das crianças à escola que aí está), ou nos aperfeiçoamentos técnicos que promovam mudanças na sua prática profissional, como muitos estudos e experiências profissionais têm alertado.

Este estudo partilha das teses de que só uma mudança no "esquema referencial", isto é, nas concepções dos profissionais acerca das crianças e famílias pobres e suas capacidades, no "conjunto de experiências, conhecimentos e afetos com os quais o indivíduo pensa e atua" (Bleger, 1985, p. 67) em relação às questões escolares, pode transformar sua prática profissional. $O$ ponto de partida precisa ser repensar a prática tal como ela está constituída, redefinindo as metas de formação profissional. Qualquer busca de caminhos alternativos para a psicologia escolar esbarra numa tarefa maior - a formaçãoteórico-conceitual através dos cursos de graduação e pós-graduação que efetivamente preparem o profissional e desenvolvam nele uma visão crítica que integre os diferentes aspectos da realidade social e política da sociedade.

Apesar do aumento crescente de publicações e relatos de experiência voltados para a revisão crítica do conhecimento acumulado pela psicologia e dos resultados positivos dos novos rumos da psicologia escolar em alguns centros de pesquisa e intervenção, o que aparece em cena ainda é uma prática profissional baseada em discursos, muitas vezes não sustentáveis do ponto de vista científico, havendo coexistência de recortes de várias teorias que utilizam modelos de intervenção baseados apenas em procedimentos técnicos e preconceitos de moda.

Assim, os resultados nos remetem a que os cursos de formação em psicologia ainda formam profissionais para atuar na solução dos problemas individuais e levam o psicólogo a acreditar que o trabalho a ser feito não é transformar uma sociedade autoritária e excludente, mas integrar à sociedade que aí está os seus membros desgarrados, delinqüentes e doentes, conforme à visão ideológica da classe domi- 
nante que pretende manter o poder, negando o saber às classes menos favorecidas..

\section{Referências}

Almeida, N. V. (1992). O psicólogo na instituição escolar: um estudo descritivo de sua prática profissional. Dissertação de mestrado nãopublicada, Universidade Federal da Paraíba, João Pessoa.

Andaló, C. (1993). O psicólogo escolar em busca de uma identidade. Jornal do Federal, 34, 5.

Balbino, V. R. (1990). Psicólogos escolares em Fortaleza: dados da formação da prática e da contextualização da atividade profissional. Psicologia: Ciência e Profissão, 2, 50-57.

Bleger, J. (1985). Temas em Psicologia: entrevistas e grupos (2 $2^{\mathrm{a}}$ ed.). São Paulo: Martins Fontes.

Bleger, J. (1992). Psico-higiene e Psicologia Institucional (3 $3^{\mathrm{a}}$ ed.). Porto Alegre: Artes Médicas.

Boarini, M. L., Guimarães, P. O., \& Luzia, F. (1990). Estudo sobre a demanda infanto-juvenil na UBS São João no município de Mauá/SP. Manuscrito não-publicado.

Boarini, M. L., \& Borges, R. F. (1998). Demanda infantil por serviços de saúde mental: sinal de crise. Estudos de Psicologia (Natal), 3, 83-108.

Bohoslavsky, R. (1997). A psicopatologia do vínculo professor-aluno: o professor como agente de socialização. In M. H. Patto (Org.), Introdução à Psicologia Escolar (pp. 357 -381). São Paulo: Casa do Psicólogo.

Carraher, T. N. (1982). Na vida dez e na escola zero: os conceitos culturais da aprendizagem da matemática. Cadernos de Pesquisa, 42, 79-86.

Collares, C., \& Moyses, M. A.(1996). Preconceito no cotidiano escolar. São Paulo: Cortez.

Costa, J. F. (1984). Psicologia e Psicanálise. Rio de Janeiro: Graal.

Del Prette, Z. A. P. (1993). A identidade do psicólogo escolar/educacional: as diferentes faces da (re)construção. Estudos de Psicologia (Campinas), 10, 125-138.

Ferreiro, E., \&Teberosky, A. (1991). Psicogênese da língua escrita. Porto Alegre: Artes Médicas.

Freller, C. (1997). Grupos de criança com queixa escolar. In A. M. Machado \& M. P. R. Souza (Orgs.). Psicologia Escolar: em busca de novos rumos (pp. 63-78). São Paulo: Casa do Psicólogo.

Gatti, B. A., Patto, M. H., Costa, M., Copit, M., \& Almeida, R. (1981). A reprovação na 1a. série do 1a.grau: um estudo de caso. Cadernos de Pesquisa, 38, 3-13.

Kupfer, M. C. M. (1992). A contribuição da Psicanálise aos estudos sobre a família e a educação. Psicologia USP, 31/2), 77-82.

Machado, M. A. (1991). Inventando uma intervenção na escola pública. Dissertação de mestrado não-publicada, Instituto de Psicologia da Universidade de São Paulo, São Paulo.
Machado, A. M., \& Souza, M. P. R. (Orgs.). (1997). Psicologia Escolar: em busca de novos rumos. São Paulo: Casa do Psicólogo.

Machado, A. M., Sayão, Y., \& Souza, M. P. R. (1997). As classes especiais e uma proposta de avaliação psicológica. Educação Especial em Debate (pp. 69-116). São Paulo: Casa do Psicólogo/CRP-06.

Mello, S. L. (1997). A formação profissional dos psicólogos: apontamentos para um estudo. In M. H. Patto (Org.), Introdução à Psicologia Escolar (pp. 441-448), São Paulo: Casa do Psicólogo.

Moffat, A. (1984). Psicoterapia do Oprimido (5 $5^{\mathrm{a}}$ ed.). São Paulo: Cortez.

Oliveira, Q., \& Bruns, M. A. T. (1992). O serviço de psicologia escolar visto pelos profissionais que atuam nas redes de ensino pública e particular de Ribeirão Preto e Região. Paidéia, 3, 40-51.

Patto, M. H. (1985). A criança da escola pública: deficiente, diferente ou mal trabalhada? Projeto IPÊ. Secretaria de Estado da Educação de São Paulo, São Paulo.

Patto, M. H. (1987). Psicologia e Ideologia: uma introdução crítica à Psicologia Escolar. São Paulo: T. A. Queiroz.

Patto M. H. (1990). A produção do fracasso escolar. São Paulo: T. A. Queiroz.

Pessotti, I. (1975). Dados para uma história da Psicologia no Brasil. Psicologia, 1, 1-14.

Piotto, D. C., Vale, P. C. S., Meneghini, R., Araújo, M., Matos, E. F., Midori, E., \& Sawaya, S. M. (1997, outubro). A produção do fracasso escolar no cotidiano: experiência de intervenção na escola pública [Resumo]. Resumos de Comunicação Científica, XXVII Reunião Anual de Psicologia, Ribeirão Preto, Brasil.

Ribeiro, S. C. (1991). A pedagogia da repetência. Revista Estudos Avançados, 5, 7-21.

Ezpeleta, J., \& Rockwell, E. (1989). Pesquisa Participante ( $2^{\underline{a}}$ ed.). São Paulo: Cortez.

Santos, M. A. (1990). Caracterização da clientela de uma clínica psicológica da Prefeitura de São Paulo. Arquivos Brasileiros de Psicologia, 42, 79-94.

Sawaya, S. M. (1999). A leitura e a escrita como práticas culturais e o fracasso escolar das crianças de classes populares: uma contribuição crítica. Tese de doutorado não-publicada, Instituto de Psicologia da USP, São Paulo.

Silva, R. C. (1994). O fracasso escolar: a quem atribuir? Paidéia, 7, 33-41.

Souza, M. P. R. (1993). Psicólogos na Saúde e na Educação: a busca de novos caminhos na compreensão da queixa escolar. Insight: Psicoterapia, 13, 25-27.

Souza, M. P. R. (1996). A queixa escolar e a formação do psicólogo. Tese de doutorado não-publicada, Instituto de Psicologia, Universidade de São Paulo, São Paulo.

Yamamoto, O. H., Oliveira, I., Silva, L., Freire, M., Rocha, R., \& Alves Filho, S. (1990). A Psicologia Escolar em Natal: características e perspectivas. Psicologia: Ciência e Profissão, 2, 40-49.

Estela Cabral é psicóloga contratada pela Prefeitura Municipal de Cajuru, exercendo função junto à Secretaria Municipal de Educação. Endereço para correspondência: Rua Luiz Gomes, 213, Jd. Paulista, 14.090-220, Ribeirão Preto, SP. E-mail: cabralestela@ hotmail.com.

Sandra Maria Sawaya, doutora em Psicologia Escolar e do Desenvolvimento Humano pela Universidade de São Paulo, é Professora Assistente Doutora do Departamento de Psicologia e Educação da FFCLRP da Universidade de São Paulo, Ribeirão Preto, SP. Endereço para correspondência: Av. Bandeirantes, 3000, Campus Universitário, Departamento de Psicologia e Educação da FFCLRP/ USP, 14.040-901, Ribeirão Preto, SP, tel. (16) 602-3795, e-mail smsawaya @ ffclrp.usp.br. 